DOMINSCHEK, Desiré Luciane. As fotografias como representação da racionalização para a formação do pequeno operário. Domínios da Imagem, Londrina, v. 12, n. 23, p. 51-67, jul./dez. 2018.

ISSN 2237-9126

\title{
AS FOTOGRAFIAS COMO REPRESENTAÇÃO DA RACIONALIZAÇÃO PARA A FORMAÇÃO DO PEQUENO OPERÁRIO
}

\section{PHOTOGRAPHS AS REPRESENTATION OF RATIONALIZATION FOR THE TRAINING OF THE SMALL WORKER}

Recebido em 29/9/2017 e aprovado em 30/11/2018

Desiré Luciane Dominschek•

\begin{abstract}
Resumo: A utilização de imagens fotográficas por historiadores vem permitindo realizar trabalhos renovadores no âmbito da história, seja da educação, da saúde ou da ciência. O objetivo desta pesquisa é apresentar as fotografias como possibilidades de novas pesquisas e novas análises em trabalhos futuros, sobre o ensino profissional no Paraná. Entendendo que cada momento histórico produz representações passíveis de serem analisadas pelo historiador e que podem propiciar outras versões da temática à historiografia, propomos a apresentação da formação de jovens aprendizes por meio de imagens fotográficas na escola do Serviço Nacional de Aprendizagem Industrial (Senai) em Curitiba, entre as décadas de 1950 a 1980. As fotografias em grande maioria produzidas por fotógrafos não identificados e/ou contratos pelo SENAI, apresentam momentos do processo de formação dos aprendizes na ótica institucional, e podem suscitar outras perspectivas de análise.
\end{abstract}

Palavras-chaves: Fotografia. SENAI. Ensino profissional

Abstract: The use of photographic images by historians has allowed us to carry out renovating works within history, be it education, health or science. The objective of this research is to present the photographs as possibilities of new researches and new analyzes in future works, on professional education in Paraná. Understanding that each historical moment produces representations

\footnotetext{
- Doutorado em Educação na área de Concentração: Filosofia e História da Educação, pela Universidade Estadual de Campinas (UNICAMP) participa do grupo de estudos; História, Sociedade e Educação no Brasil; (HISTEDBR).Mestre em Educação na área de concentração: História e Historiografia da Educação, pela Universidade Federal do Paraná (UFPR).Especialista em Organização do Trabalho Pedagógico e Ciência Política pela (UFPR) ;graduada em pedagogia pela mesma instituição. Professora de História da Educação do Centro Universitário Internacional Uninter. Atuando nos seguintes temas: história das instituições escolares, história do ensino profissional, reflexões sobre a pesquisa e prática pedagógica. Atualmente coordena o setor de Pesquisa e publicações acadêmicas e o Comitê de Ética da Uninter, também é coordenadora Institucional do Programa de Iniciação a docência e do Programa de Residência Pedagógica UNINTER - Pertence as seguintes associações acadêmicas : Sociedade Brasileira de História da Educação - SBHE ,Associação Nacional de História - ANPUH, Associação Nacional de Pós-Graduação em Educação - ANPED, Sociedade Brasileira para o Progresso da Ciência - SBPC
} 
DOMINSCHEK, Desiré Luciane. As fotografias como representação da racionalização para a formação do pequeno operário. Domínios da Imagem, Londrina, v. 12, n. 23, p. 51-67, jul./dez. 2018.

ISSN 2237-9126

that can be analyzed by the historian and that can propitiate other versions of the subject to historiography, we propose the presentation of the formation of young apprentices through photographic images in the school of the National Service of Industrial Learning (Senai) in Curitiba, Between the 1950s and 1980s. Photographs that are mostly produced by unidentified photographers and / or contracts by SENAI present moments of the process of training apprentices in the institutional perspective, and may give rise to other perspectives of analysis.

Keywords: Photography. SENAI. Vocational education.

\section{Fotografias e as possibilidades de Pesquisa}

A imagem pose ser flou, deformada, descolorida, sem valor documentário, procede por sua gênese da ontologia do modelo; é o modelo. Daí o encanto dessas fotografias de álbuns. Essas sombras, cinza ou sépia, fantasmásticas, quase ilegíveis, não são mais os retratos tradicionais de família. São a presença perturbadora de vidas detidas em sua duração, libertas de seu destino, não pelos prestígios da arte, mas pela virtude de uma mecânica impassível. A fotografia não cria, como arte, a eternidade, não embalsama o tempo, apenas o subtrai de sua primeira corrupção(...a fotografia beneficia-se de sua transparência de realidade da coisa para sua superprodução. (BAZIN apud DUBOIS, 1994, p. 80)

Entendendo que cada momento histórico produz representações passíveis de serem analisadas pelo historiador e que podem propiciar outras versões da temática à historiografia, propomos a apresentação da formação de jovens aprendizes por meio de imagens fotográficas na escola do Serviço Nacional de Aprendizagem Industrial (SENAI) em Curitiba, entre as décadas de 1950 a 1980.

A utilização de imagens fotográficas por historiadores vem permitindo realizar trabalhos renovadores no âmbito da história, seja da educação, da saúde ou da ciência. O objetivo desta seção é apresentar as fotografias ${ }^{1}$

\footnotetext{
1 Fotografias resgatadas no período da pesquisa para o doutorado no Centro de Memória do SENAI-PR.
} 
DOMINSCHEK, Desiré Luciane. As fotografias como representação da racionalização para a formação do pequeno operário. Domínios da Imagem, Londrina, v. 12, n. 23, p. 51-67, jul./dez. 2018.

ISSN 2237-9126

como possibilidades de novas pesquisas e novas análises em trabalhos futuros, visto que nem todas as imagens puderam ser analisas/utilizadas na pesquisa.

Moraes e Vidal (2002) ${ }^{2}$ destacam a partir de estudos de Kossoy e Ciavatta, que a história da fotografia no Brasil, possibilita entender algumas das opções fotográficas, por exemplo a adoção de padrões formais típicos, como a apropriação da preservação da memória documental e também da memória fotográfica. As autoras destacam que os fatores de ordem cultural e econômico impediram que, ao lado da grande expansão da produção fotográfica na segunda metade do século $X X$, também se desenvolvesse 0 registro e a preservação da memória além do âmbito familiar.

A fotografia surgiu no Brasil por volta de 1833 e, a partir dos anos de 1850, com a descoberta do cartão de visita fotográfico (carte-de-visite), difundiu-se, atingindo inclusive as classes menos abastadas. A superação das dificuldades tecnológicas, em 1881, com a invenção da câmara portátil alterou o perfil do fotografo e da fotografia. Não apenas popularizou 0 fotoamadorismo, aumentando o número de fotógrafos em atividade, como tornaram-se mais frequentes os registros de paisagens, e dentre eles os de fachadas na fotografia urbana. No final do século XIX, o uso social da fotografia foi ampliado através da invenção de novo sistema de reprodução fotomecânica, permitindo a impressão de fotos em publicações e cartões postais, superando a litografia e dando origem ao fotojornalismo (LOBO, $1997^{3}$ apud MORAES; VIDAL, 2002, p.15).

Como outras fontes de pesquisa a fotografia permite analisar relações, podendo direcionar, enriquecer a variedade das fontes com as quais o historiador atual. Importante também destacar o uso de imagens (fotografias) como fontes, pois estas não apenas ilustram o texto, mas fazem parte do mesmo. Na interpretação de Kossoy (2001) é preciso atentar para as múltiplas faces e realidades da imagem fotográfica. Ele chama a atenção para as

\footnotetext{
2 Texto Fotografia e Escola: alguns desafios á análise histórica e ao tratamento documental disponível no livro - Escolas Profissionais Públicas do Estado de São Paulo: uma história em Imagens - álbum fotográfico - 2002.

3 Originalmente citado por Vidal (1998).
} 
DOMINSCHEK, Desiré Luciane. As fotografias como representação da racionalização para a formação do pequeno operário. Domínios da Imagem, Londrina, v. 12, n. 23, p. 51-67, jul./dez. 2018.

ISSN 2237-9126

dimensões da fotografia como memória e representação, fruto de uma elaboração cultural, estética e técnica.

Barros (2005), destaca a quem das fotografias no cotidiano escolar. $\bigcirc$ autor coloca a seguinte questão: $O$ mundo escolar produz imagens? Para Barros a resposta não é difícil, pois a partir da pergunta podemos nos lembrar de gravuras, desenhos, fotografias que ilustram os textos escritos em nossos livros didáticos.

Segundo Barros (2005) as fotografias produzidas pelas instituições escolares em grande maioria falam de uma história oficial, produzida pelo governo, no caso das escolas federais, estaduais municipais, ou mantenedoras religiosas ou laicas, no caso de instituições particulares. As fotos deste universo são produzidas por fotógrafos profissionais, impondo uma estética apurada no tratamento formal ( planos de fundo, distribuição da figuração), com um conteúdo fundado em signos que remetem á tradição humanista secular e á disciplina e moral religiosa.

Para Barros (2005), foi na segunda metade do século XIX, que se iniciou a transição pelo universo das imagens e o que pode ser chamado de cartões postais escolares, que traziam o cotidiano de escolas em todos os níveis.

Nelas, em sua maioria encontramos imagens das fachadas dos prédios escolares, e no verso, propagandas sobre a excelência no ensino, da disciplina, da competência moralizadora e conteudista de seus professores. Como recurso muito presente nessa longa duração da fotografia escolar, nos postais escolares as imagens associam a arquitetura á modernidade das propostas pedagógicas. Mesmo na atualidade do século XXI, permanece o recurso ás fotografias como propaganda institucional, associando a modernidade dos prédios dos Centros de Informação escolar e profissional (Cieps) e dos Centros integrados de Apoio á criança (Ciacs) á proposta democrática de ensino formulada pelo Estado. (BARROS, 2005, p.122)

Borges (2008) enfatiza que nos primeiros anos do aparecimento da fotografia, os fotógrafos eram em maioria homens, tidos como desenhistas, gravuristas autodidatas, caricaturistas, pintores, eles não tinham vínculo direto 
DOMINSCHEK, Desiré Luciane. As fotografias como representação da racionalização para a formação do pequeno operário. Domínios da Imagem, Londrina, v. 12, n. 23, p. 51-67, jul./dez. 2018.

ISSN 2237-9126

com academias e suas imagens traziam temas distantes da ação dos homens considerados produtores da História. A autora ainda destaca que, por exemplo, no caso de caricaturas, as imagens tinham como objetivo maior a crítica das ações de poder, funcionando como uma contra história, crítica aos documentos oficiais.

Cabe explicitar que,

Essa dilatação do uso da fotografia faz com que os novos fotógrafos estabeleçam novos e distintos critérios de olhar para fazer suas tomadas dos acontecimentos sociais. Cada indivíduo define não apenas o que merece ser registrado, mas também sob que ângulo as ações sociais de seus cotidianos devem ser imortalizadas (BORGES, 2008, p.30).

O século XX inaugura uma nova fase do trabalho com imagens no cotidiano das escolas, o foco das fotografias enfatiza os conteúdos curriculares e suas práticas de ensino - exposição de trabalhos manuais, apresentações de educação física, oficinas. Também destacam-se as atividades extraclasse, refletindo o índice de uma "boa pedagogia": refeições disciplinadas, formações diárias para o hasteamento da bandeira e canto do hino nacional. Barros (2005), ainda completa "a aparente concentração dos discentes em si mesmos, disciplinados e ordeiros, indiciava a competência da instituição em sua pedagogia exemplificadora" (p.122)

Ainda refletindo sobre a produção das fotos oficiais4,

As fotos oficiais também remetiam a eventos solenes - desfiles, homenagens, formaturas, visitas de personalidades, datas cívicas. Todavia, entre essas imagens há uma que tem grande apelo á nossa memória: elas sempre estamos sozinhos, sentados em carteiras, tendo á frente o nome da escola, cercados por signos e símbolos da educação escolar. (BARROS, 2005, p.122)

\footnotetext{
${ }^{4}$ Nem só de imagens oficiais, produzidas pelas instituições escolares, é feita a iconografia disponível para o historiador. Existem as fotografias produzidas pela esfera do privado :a exemplo dos álbuns particulares de família. (Barros,2005)
} 
DOMINSCHEK, Desiré Luciane. As fotografias como representação da racionalização para a formação do pequeno operário. Domínios da Imagem, Londrina, v. 12, n. 23, p. 51-67, jul./dez. 2018.

ISSN 2237-9126

Aspectos que verificamos nas imagens e fotografias produzidas nas escolas do SENAI-PR. As fotografias em grande maioria produzidas por fotógrafos não identificados e/OU contratos pelo SENAI-PR, apresentam momentos do processo de formação dos aprendizes na ótica institucional, e podem suscitar outras perspectivas de análise. As fotografias figuram o retrato das máquinas nos aprendizes, ou seja, máquinas azeitadas e em ótimas condições, aprendizes higienizados e paramentados para o trabalho.

Figura 1 - curso de Modista

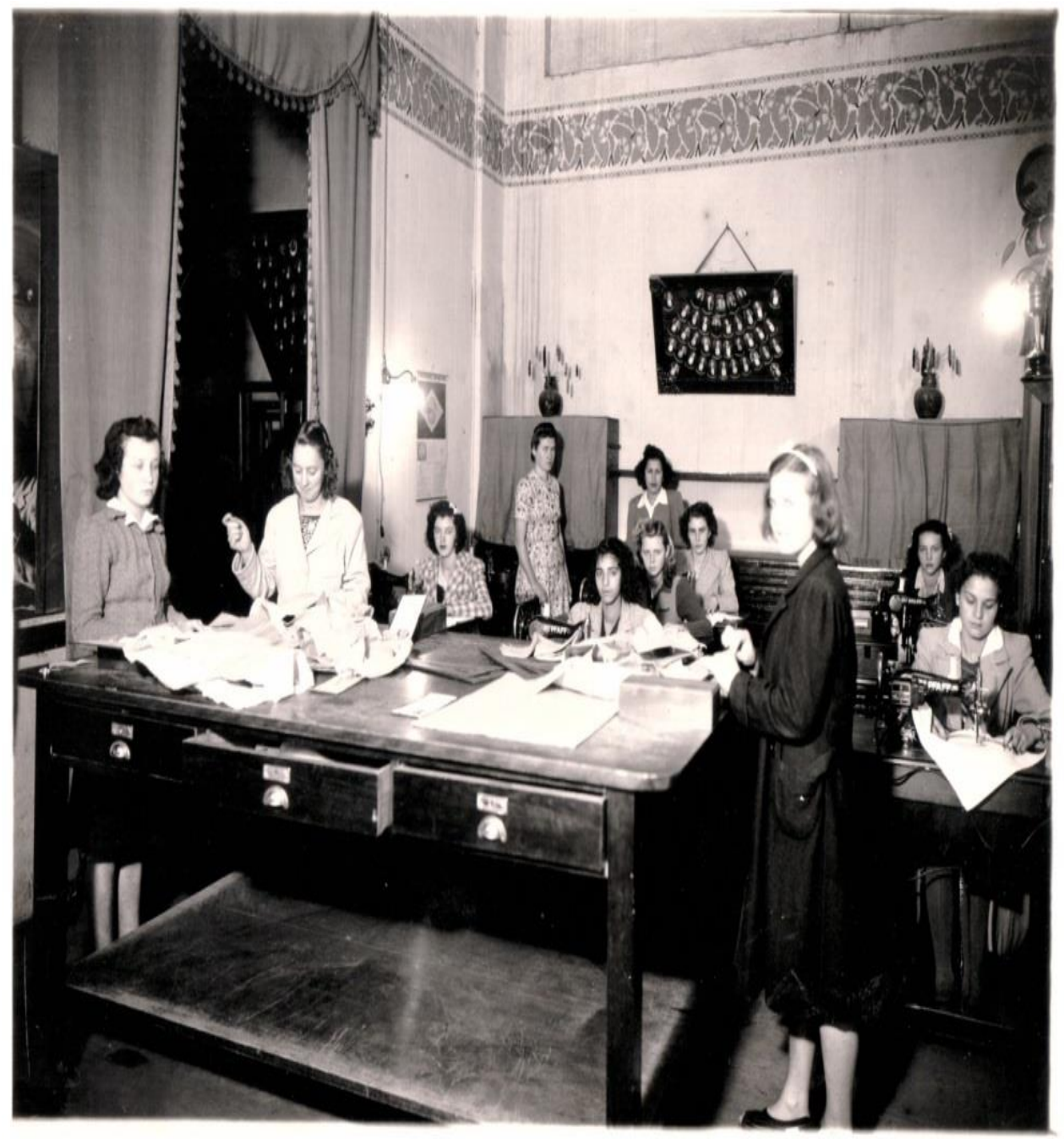

Curso de Modista, 1946 - Curitiba, 1946

Fonte: Centro de Memória do SENAI-PR 
DOMINSCHEK, Desiré Luciane. As fotografias como representação da racionalização para a formação do pequeno operário. Domínios da Imagem, Londrina, v. 12, n. 23, p. 51-67, jul./dez. 2018.

ISSN 2237-9126

A produção de fotografias sobre o ensino e ou educação profissional foi mais restrita, visto que os registros fotográficos pelas instituições escolares variaram em sua composição e mensagem ao longo de todo o século XX, muitas das produções fotográficas eram encomendadas pelo governo, nas escolas públicas e outras por mantenedoras particulares. Diferentemente das escolas públicas, as escolas particulares primarias praticamente silenciavam sobre a existência de um ensino profissional, inexistindo fotografias de atividades pedagógicas, curriculares ou complementares, preparatórios para uma terminalidade que implicasse uma habilitação profissional. (BARROS, 2005)

Para Ciavatta (2002, p.16)

Se a imagem acompanha a vida humana como representação da realidade, como memória e expressão da cultura de um povo, de uma época, garantia de uma visão do passado, hoje com a comunicação informatizada, ela nos desafia a compreendê-la em novas temporalidades como mediação complexa dos processos.

O uso de fotografias como fonte de pesquisa histórica se insere conforme Mauad, descreve no prefácio do livro de Ciavatta (2002), Mathew Brady, chefe da equipe fotográfica que cobriu a Guerra Civil norte americana, relaciona a câmera fotográfica com a seguinte expressão: O olho da História.

As fotografias produzidas nos campos de batalha eram consideradas como verdadeiras testemunhas oculares da história, pois desnudavam em imagens a dura realidade da guerra de maneira bem diversa dos escritos. A imagem fotográfica, segundo a concepção oitocentista, era assimilada a partir da crença de que as fotografias não passavam de janelas que se abriam para o mundo lá fora, expondo-o da maneira mais fidedigna possível. Portanto, tudo o que era visto era percebido como tal. O relato histórico ganhava, assim, a força comprobatória da verdade fotográfica (MAUAD, 2011, p.7). 
DOMINSCHEK, Desiré Luciane. As fotografias como representação da racionalização para a formação do pequeno operário. Domínios da Imagem, Londrina, v. 12, n. 23, p. 51-67, jul./dez. 2018.

ISSN 2237-9126

A partir da década de 1930 com a modernização técnica da imprensa e a associação de agências governamentais, Mauad (2011) destaca que é possível contar a história do século XX a partir de imagens.

Tais fotografias compõem um catálogo no qual surge uma história redefinida pelo estatuto técnico próprio ao dispositivo da representação: a câmara fotográfica. Nesse outro tipo de história local de sua produção (as agências de produção da imagem: família, Estado e imprensa) e o sujeito da narrativa (Os fotógrafos), dividem com os institutos históricos e as academias literárias, a tarefa de imaginar a nação e instituir os lugares de memória. (MAUAD, 2011, p.7).

Sobre a representação da fotografia Barthes (1984) destaca que,

Desde o primeiro passo, o da classificação (é preciso classificar, realizar amostragens, caso se queira constituir um corpus), a Fotografia se esquiva. As divisões ás quais ela é submetida são de fato ou empíricas (profissionais/Amadores), ou retóricas (Paisagens/ Objetos/Retratos/Nus), ou estéticas (Realismo/Pictorialismo), de qualquer modo exteriores ao objeto, sem relação com sua essência, que só pode ser (caso exista) o Novo de que ela foi advento, pois essas classificações poderiam muito bem aplicar-se a outras formas antigas, de representação. Diríamos que a Fotografia é inclassificável (BARTHES, 1984, p.12-13).

O autor acima citado afirma ainda que a fotografia como representação da realidade, reproduz ao infinito o que ocorreu uma única vez, "ela repete mecanicamente o que nunca mais poderá repetir-se existencialmente" (1984, p.13) o autor assim reafirma a necessidade do significado do que a fotografia representa

Tal foto, com efeito, jamais se distingue de seu referente (do que ela representa), ou pelo menos não se distingui dele de imediato o para todo mundo (o que é feito por qualquer outra imagem, sobrecarregada, desde o início e por estatuto, com o modo o objeto é simulado): perceber o significante fotográfico não é impossível (isso é feito por profissionais), mas exige um ato 
DOMINSCHEK, Desiré Luciane. As fotografias como representação da racionalização para a formação do pequeno operário. Domínios da Imagem, Londrina, v. 12, n. 23, p. 51-67, jul./dez. 2018.

ISSN 2237-9126

segundo de saber ou de reflexão. Por natureza, a fotografia é preciso por comodidade aceitar esse universal, que por enquanto apenas remete a repetição incansável da contingência tem algo de tautológico: um cachimbo, nela, é sempre cachimbo, intransigentemente. Diríamos que a Fotografia sempre traz consigo seu referente, ambos atingidos pela mesma imobilidade amorosa ou fúnebre, no âmago do mundo em movimento; estão colados um ao outro, membro por membro [...] (BARTHES, 1984, p.14-15).

Nas fotografias percebe-se em primeira instância o progresso do processo de criação e desenvolvimento do SENAI no Paraná, e seus sujeitos; os aprendizes e seus ofícios, questões que foram constantemente analisadas neste trabalho.

Uma das grandes dificuldades que a fotografia impõe ao seu tratamento como fonte consiste em superar a contemplação estética, o encantamento exercido pela imagem, e apreendela enquanto produção de significados, cuja análise - a partir da contribuição da semiótica, da antropologia e da sociologia envolve o conhecimento do fotografo, dos agentes contratantes, dos recursos tecnológicos disponíveis e das condições sócio-históricas em que foi efetuado o registro. Em outras palavras, se não se pode negar que a fotografia traz elementos para a construção da história e da história da educação do fim do século XIX e especialmente, do século XX, não se pode assumir a imagem como registro neutro (MORAES e VIDAL, 2002, p.15).

Mauad (2011), afirma que a "ideia de testemunha ocular ganha força representacional de forma inusitada, com a generalização do uso da fotografia em diferentes modalidades de registro da experiência pessoal." (p.111) Concordamos como a autora que a imagem é testemunha de uma história, mas não sejamos ingênuos que estas evidências históricas são "peixes no oceano", a captação casual da imagem pelo olhar neutro do fotógrafo é ingênua, mas a evidência histórica e a imagem são constituídas por investimentos de sentidos. Assim a fotografia é uma pista, um documento para se produzir ou reproduzir a história, a foto nos possibilita conhecer situações passadas sendo ela mesma um saber-fazer (MAUAD, 2011). 
DOMINSCHEK, Desiré Luciane. As fotografias como representação da racionalização para a formação do pequeno operário. Domínios da Imagem, Londrina, v. 12, n. 23, p. 51-67, jul./dez. 2018.

ISSN 2237-9126

Figura 2 - Oficina de Artes gráficas

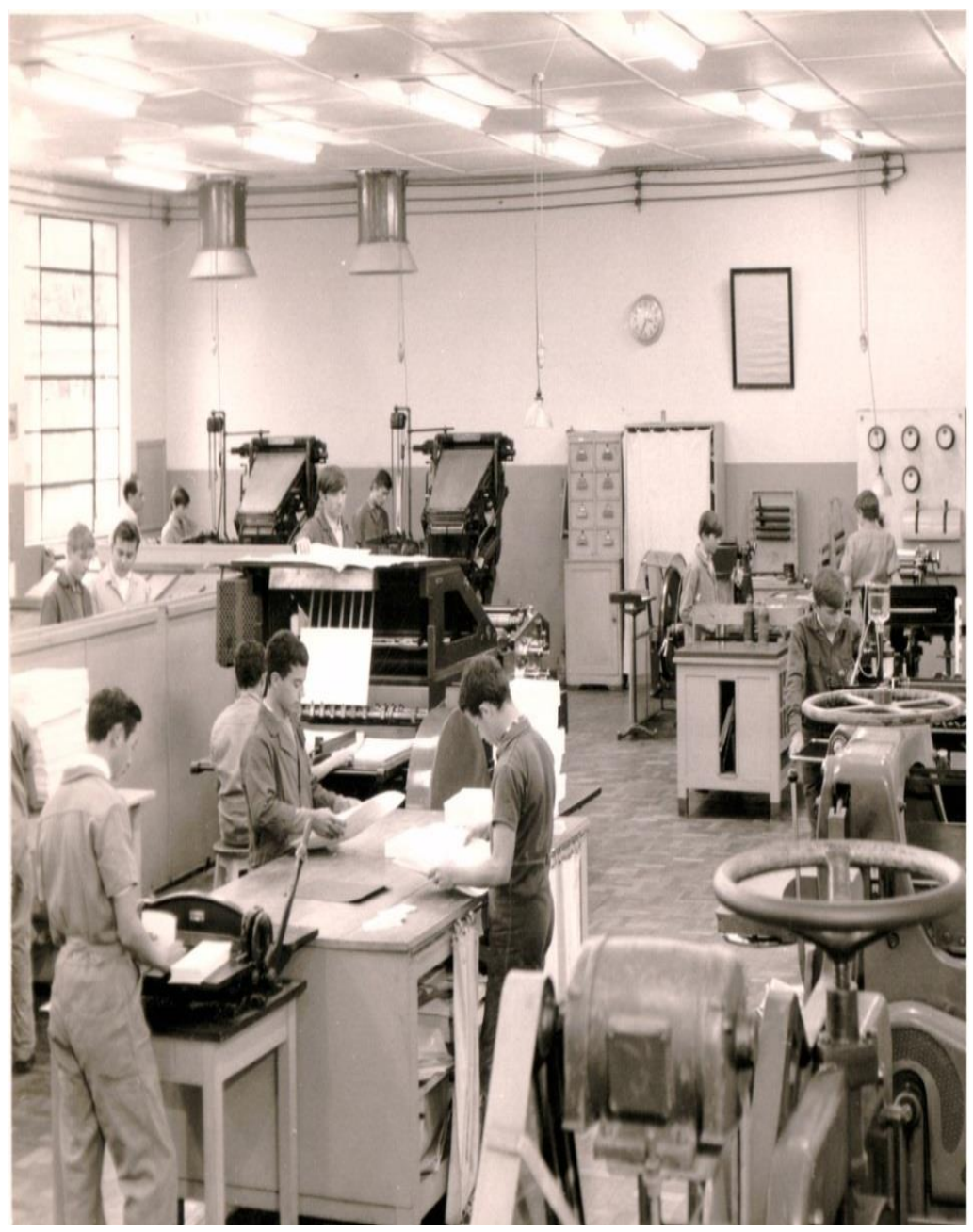

Fonte: Centro de Memória do SENAI-PR

A ideia de um álbum iconográfico sobre a história do ensino profissional das escolas do SENAI-PR apresenta o recuo aos primeiros anos de criação das escolas do SENAI-PR, seus espaços, seus tempos ao longo das décadas de 
DOMINSCHEK, Desiré Luciane. As fotografias como representação da racionalização para a formação do pequeno operário. Domínios da Imagem, Londrina, v. 12, n. 23, p. 51-67, jul./dez. 2018.

ISSN 2237-9126

existência, as pessoas ali envolvidas: alunos aprendizes, professores, instrutores, empresários, industriais.

As fotografias trazem o contexto do que foi vivido, e possibilitam-nos interrogações objetivas sobre o passado vivido.

Figura 3 - Curso de serralheria

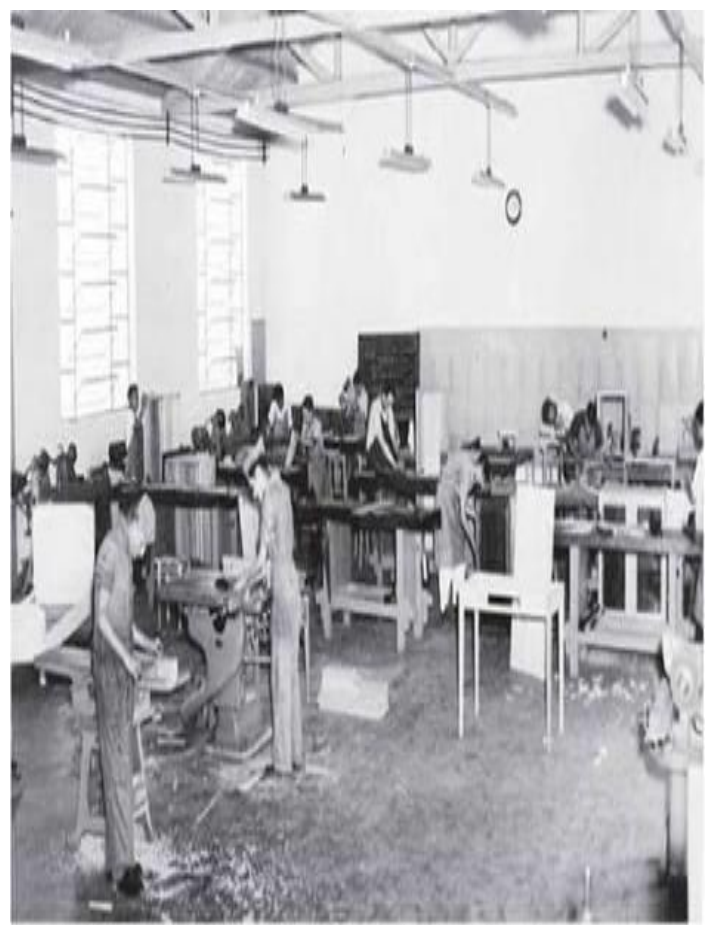

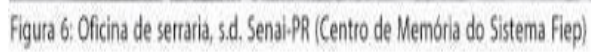

Fonte: Centro de Memória do SENAI-PR

Apoiamo-nos em Moraes e Vidal, quando se reportam sobre o uso metodológico da fotografia como fonte histórica,

[...] pretendeu-se apontar as preocupações de ordem metodológica que o uso da fotografia suscita no trabalho historiográfico da educação, destacando narrativas imagéticas diferem de outras narrativas e impõem uma metodologia singular de tratamento e análise. Não houve a intenção de, com isso, retirar o véu delicado e sensível que 
DOMINSCHEK, Desiré Luciane. As fotografias como representação da racionalização para a formação do pequeno operário. Domínios da Imagem, Londrina, v. 12, n. 23, p. 51-67, jul./dez. 2018.

ISSN 2237-9126

envolve a contemplação e o estudo das fotografias, remetendo para o campo da pura razão cartesiana o olhar acadêmico. Procurou-se destacar, apenas, que o belo do registro fotográfico, para além de emocionar, representa, produzindo imagens cujo significado não pode ser apreendido nelas mesmas, na sua materialidade imediata. Enquanto construção de sentido radicalmente histórica supõe o desvelamento de sua produção e apropriação criativa pelos sujeitos (MORAES e VIDAL, 2002, p.16).

Abaixo, poderemos ver cenas das oficinas, das salas de aula, pátios, fachadas de prédios, dos aprendizes e professores, essas fotografias contribuem para a formação de uma história em imagens sobre o ensino profissional nas escolas do SENAI-PR.

As fotografias, portanto, podem transformar-se em fontes históricas iconográficas, possibilitando a pesquisa sobre 0 mundo escolar em determinada época e espaço, remetendo ao vestuário, aos tipos étnicos, á composição sexual, á arquitetura escolar, aos materiais e recursos pedagógicos, desde que relacionados a fontes de outras naturezas (escrita, orais), quando organizadas em séries temáticas - agrupadas por períodos, fotógrafos, contratantes, comunidade ledora podem sugerir discursos não verbais, indiciando campos discursivos nos quais estão presentes ideologias, estéticas, enfim, uma gnose que organiza e da sentido a visualidade. (BARROS, 2005, p. 129)

As fotografias reunidas em um "álbum iconográfico" 5 pretendem sugerir possibilidades de pesquisas para os estudiosos da área de História da Educação, especialmente, os estudiosos que analisam as relações de trabalho e educação no ensino profissional das escolas do SENAI-PR. As imagens apresentadas são situadas como documentação fotográfica e

50 termo Album iconográfico foi utilizado para apresentar as imagens pesquisadas no Centro de Memória do SENAI-PR, ver a tese: A FORMAÇĀO DO PEQUENO OPERÁRIO NA ESCOLA SENAIPR - A REPRODUÇÃO IDEOLOGICA PRESENTE NO JORNAL “ O ESCUDO" defendia em 2017 pela Universidade Estadual de Campinas-UNICAMP. 
DOMINSCHEK, Desiré Luciane. As fotografias como representação da racionalização para a formação do pequeno operário. Domínios da Imagem, Londrina, v. 12, n. 23, p. 51-67, jul./dez. 2018.

ISSN 2237-9126

podem representar pistas e vestígios sobre o passado do ensino profissional das escolas desta instituição.

Como outras fontes de pesquisa, a fotografia enseja compreender pelo olhar, permite analisar relações, e pode ampliar e enriquecer a variedade de fontes com as quais o historiador trabalha.

Se a imagem acompanha a vida humana como representação da realidade, como memória e expressão da cultura de um povo, de uma época, garantia de uma visão do passado, hoje, com a comunicação informatizada, ela nos desafia a compreendê-la em novas temporalidades, como mediação complexa dos processos educativos (CIAVATTA, 2002, p.18).

Utilizamos imagens do acervo composto e guardado no Centro de Memória, localizada na sede da Federação das Indústrias do Estado do Paraná (FIEP), que podem ser confrontadas e questionadas com fontes escritas (relatórios, boletins, periódicos) e ainda com documentos existentes no Arquivo Edgar Levenroth e na Biblioteca do Instituto de Filosofia e Ciências Humanas (IFCH), da Unicamp.

Figura 4 -Oficina de Alfaiataria 
DOMINSCHEK, Desiré Luciane. As fotografias como representação da racionalização para a formação do pequeno operário. Domínios da Imagem, Londrina, v. 12, n. 23, p. 51-67, jul./dez. 2018.

ISSN 2237-9126

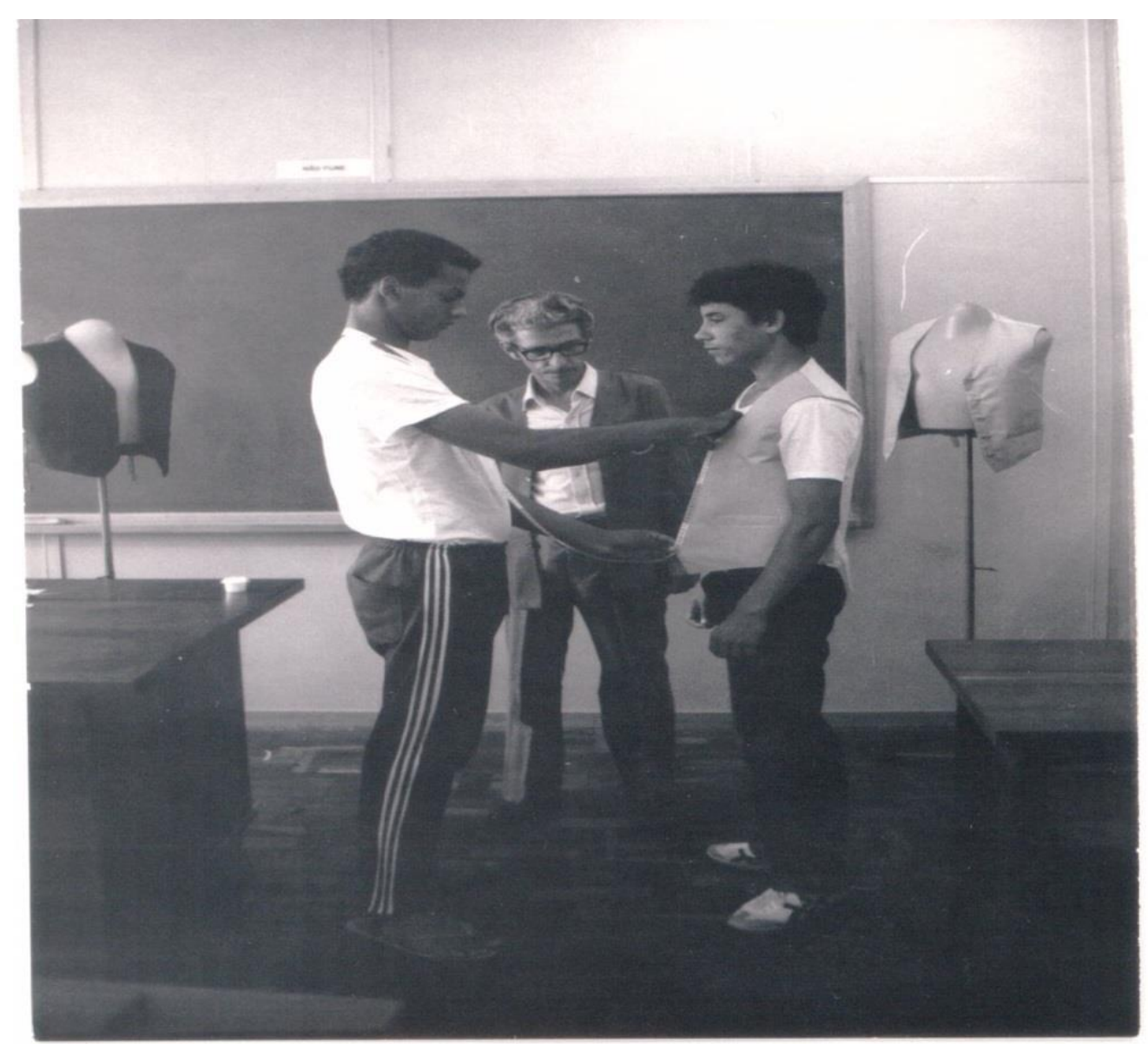

Curso de Alfaiataria - Curitiba, 1983

Fonte: Centro de Memória do SENAI-PR

As imagens são pontuadas pela leitura de documentos produzidos pelo SENAI, pela produção de historiadores ou pelo periódico editado pelos alunos. Marques e Dominschek (2011) afirmam que as fotografias eram produzidas por fotógrafos não identificados e contratados pelo SENAI, as fotografias apresentam momentos diversos do processo de formação na perspectiva institucional, ou seja, como o SENAI queria dar-se a conhecer, difundir-se pelas imagens que divulgava. Trata-se do que Peter Burke (2004) chamaria de um processo em que "artista e modelo geralmente se faziam cúmplices".

Figura 5 -Oficina de costura 
DOMINSCHEK, Desiré LUciane. As fotografias como representação da racionalização para a formação do pequeno operário. Domínios da Imagem, Londrina, v. 12, n. 23, p. 51-67, jul./dez. 2018.

ISSN 2237-9126

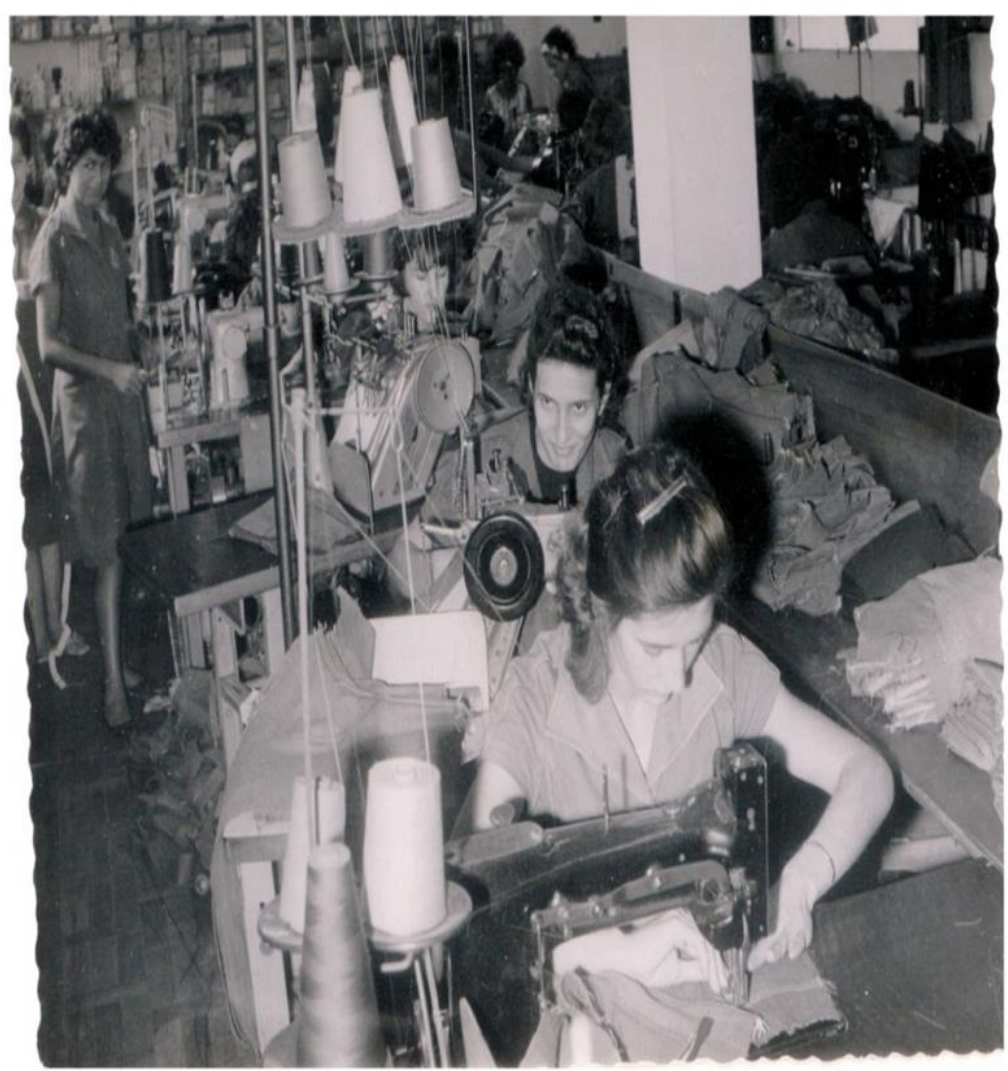

Oficina de Costura: treinamento de menores na industria Curitex Ltda. Curitiba, 1962

Fonte: Centro de Memória do SENAI-PR

O princípio que orientou a seleção e apresentação das imagens é conferido pela máxima que norteava os cursos formadores de aprendizes: instrução racional para meninos pobres, imbuídos do espírito de que 'homens certos nos lugares certos' poderiam render mais e melhor, privilegiavam conformar corpos higienizados à imagem de máquinas bem azeitadas, para que assim pudessem atender ao processo produtivo.

Conforme reflete Ciavatta (2009), historicamente, o ser humano utilizou-se dos bens da natureza por intermédio do trabalho e, produz os meios de sobrevivência e conhecimento. Posto a serviço de outrem, no entanto, nas formas sociais de dominação, o trabalho ganha um sentido ambivalente. Este é o caso das sociedades antigas e suas formas servis e escravistas, e das 
DOMINSCHEK, Desiré Luciane. As fotografias como representação da racionalização para a formação do pequeno operário. Domínios da Imagem, Londrina, v. 12, n. 23, p. 51-67, jul./dez. 2018.

ISSN 2237-9126

sociedades modernas e contemporâneas capitalistas, e neste sentido é inerente a necessidade de investigar os processos de educação e trabalho no Brasil.

As fotografias que retratam as escolas do SENAI-PR, utilizadas como fonte de pesquisa, reforçam as premissas de uma educação em que estudo, trabalho, família, pátria, calendário cívico e religioso encontravam-se alinhados, buscando constituir um todo articulado, reforçando a formação ideológica implementada na escola no desenvolvimento do ensino profissional, conforme destaca Dominschek (2015). Aspectos técnicos mesclavam-se com ordem, disciplina, saúde e hierarquia, questões que necessitam ainda de análises e reflexões no caminhar da história da educação brasileira.

\section{Referências}

1. Fontes primárias

O ESCUDO - Órgão oficial dos alunos do SENAI. Curitiba: Oficina de Artes Gráficas da Escola do SENAI, 1949-1990.

SENAI. Departamento Regional do Paraná. Senai 70 anos: 70 anos de educação, tecnologia e inovação, Curitiba: Senai,2014.

Histórias e percursos: o departamento nacional do SENAI (1942-2002).

Brasília, 2002. 
DOMINSCHEK, Desiré Luciane. As fotografias como representação da racionalização para a formação do pequeno operário. Domínios da Imagem, Londrina, v. 12, n. 23, p. 51-67, jul./dez. 2018.

ISSN 2237-9126

O Giz e a graxa: meio século de educação para o trabalho/projeto Memória SENAI-SP. São Paulo: SENAl, 1992.

2. Bibliografia

BARROS, Armando Martins de. Os Álbuns fotográficos com motivos escolares Veredas ao olhar. In: GATTI JUNIOR, Décio et. al. História da educação em perspectiva: ensino, pesquisa, produção e novas investigações. Campinas: Autores e Associados; EDUFU , 2005.

BARTHES, Roland. A Câmara clara: nota sobre a fotografia. Trad. Castanon Guimarães. Rio de Janeiro: Nova Fronteira, 1984.

BORGES, Maria Eliza Linhares. História e Fotografia. Belo Horizonte: Autêntica,2008.

CIAVATTA, Maria. Mediações históricas de trabalho e educação: gênese e disputas na formação dos trabalhadores. Rio de Janeiro: Lamparita, 2009.

O mundo do trabalho em imagens: a fotografía como fonte histórica (Rio de janeiro 1900-1930). Rio de Janeiro: DP\&A, 2002.

DOMINSCHEK, Desiré Luciane. Tempos "modernos" no Brasil? O parque fabril brasileiro e as iniciativas senasianas. In: BATISTA, Eraldo Leme; MULLER, Meire Terezinha (Org.). Realidades da Educação Profissional no Brasil. São Paulo: Ícone, 2015.

DOMINSCHEK, Desiré LUciane. A formação do pequeno operário na escola SENAI-PR - a reprodução ideológica presente no jornal "O Escudo". Tese (Doutorado em Educação) - Faculdade de Educação, Universidade Estadual de Campinas, Campinas. 2017.

MARQUES, Vera Regina Beltrão; DOMINSCHEK, Desiré Luciane. Formar e assistir: Imagens da escola do SENAl em Curitiba nas décadas de 194 e 1950. História, Ciências, saúde, v.1, n.1, 2011.

MAUAD, A. M. Olhos para ver e conhecer : fotografia e os sentidos da história. In: GAWRYSZEWSKI, Alberto et. al. (Org.) Imagem em Debate. Londrina: 2011. 
DOMINSCHEK, Desiré Luciane. As fotografias como representação da racionalização para a formação do pequeno operário. Domínios da Imagem, Londrina, v. 12, n. 23, p. 51-67, jul./dez. 2018.

MANFREDI, Silvia Maria. Educação Profissional no Brasil. São Paulo: Cortez, 2002.

MORAES, Carmem Sylvia Vidigal. O ideário republicano e a educação: uma contribuição à história das instituições. Campinas: Mercado das letras, 2006.

; VIDAL, Diana. Fotografia de Escola: alguns desafios à análise histórica e ao tratamento documental. In: MORAES, Carmen Sylvia Vidigal et al (Org.). Escolas profissionais públicas do Estado de São Paulo: uma história em Imagens - Álbum Fotográfico. São Paulo: Centro Paula de Souza, 2002.

MORAES, Carmen Sylvia Vidigal. Introdução "popular" e ensino profissional: uma perspectiva histórica. In: VIDAL, Diana. G et al (Org.). Brasil 500 anos em História da educação. São Paulo: USP, 2002. 